\title{
Antineutrophil cytoplasmic antibodies in Wegener's granulomatosis
}

\author{
S N Wong, V Shah, M J Dillon
}

\begin{abstract}
The prevalence of antineutrophil cytoplasmic antibodies (ANCA) was studied in 12 children with Wegener's granulomatosis. The serum samples were taken in the active phase of disease and were screened for ANCA by indirect immunofluorescence with normal neutrophils and enzyme linked immunosorbent assay (ELISA) using crude neutrophil extract, proteinase 3, myeloperoxidase, cathepsin G, lactoferrin, and elastase as antigens. Of these 12 patients, 10 were positive for ANCA in the active phase of their illness, and they showed a predominantly cytoplasmic ANCA staining pattern on indirect immunofluorescence. There were high titres of ANCA directed against crude neutrophil extract, proteinase 3, myeloperoxidase, and cathepsin G. IgM isotypes occurred as commonly as IgG isotypes. Therefore, screening for ANCA is usually but not invariably positive in children with Wegener's granulomatosis. Specific diagnosis still relies on clinical and pathological features, and the value of ANCA in the diagnosis of paediatric Wegener's granulomatosis requires further study.
\end{abstract}

(Arch Dis Child 1998;79:246-250)

Keywords: antineutrophil cytoplasmic antibodies; Wegener's granulomatosis

Wegener's granulomatosis is a disorder characterised by granulomatous inflammation and necrotising vasculitis in various organs. ${ }^{1}$ Clinically, it manifests as a febrile multisystem illness with particular involvement of the upper and lower respiratory tracts and kidneys. Since the late 1980 s, there have been reports of the occurrence of antineutrophil cytoplasmic antibodies (ANCA) in these patients. ${ }^{2-4}$ In adult patients, these autoantibodies help in diagnosis, ${ }^{5}$ in monitoring disease activity, and in guiding treatment. ${ }^{6}$ They have also been shown experimentally to activate human neutrophils, and might be related to the pathogenesis of Wegener's granulomatosis and similar disorders. ${ }^{78}$ In most cases the autoantibodies are directed against proteinase $3 .{ }^{9}$ In children, there have been isolated reports of ANCA in Wegener's granulomatosis and other vasculitides, ${ }^{10}{ }^{11}$ but their clinical significance remains uncertain.

Our paper reports the prevalence of ANCA in children with Wegener's granulomatosis diagnosed at Great Ormond Street Children's Hospital by indirect immunofluorescence and enzyme linked immunosorbent assay (ELISA), and the antigenic specificities and immunoglobulin isotypes of such antibodies. The usefulness and limitations of ANCA in the diagnosis of Wegener's granulomatosis in children are discussed.

\section{Patients and methods}

The study population consisted of 12 children with Wegener's granulomatosis diagnosed at Great Ormond Street Children's Hospital, London, between January 1986 and December 1991. There were four boys and eight girls. Their age of onset ranged from 2 months to 14.2 years. They had multisystem manifestations as shown in table 1. Diagnosis of Wegener's granulomatosis was established by the presence of two or more criteria according to the American College of Rheumatology. ${ }^{12}$ There was histological evidence of granulomatous inflammation or necrotising vasculitis in the nose, larynx, muscles, colon, or kidneys in seven patients.

All patients were in the active phase of their illness as shown by symptoms, a high erythrocyte sedimentation rate, and high concentrations of $\mathrm{C}$ reactive protein. Sera were obtained before immunosuppressive treatment was begun. Antinuclear factor was screened by immunofluorescence staining in rat liver cells and was positive in low titres $(<1 / 80)$ in four patients. Anti-DNA antibodies, rheumatoid factor, and other non-organ specific antibodies were also negative in all patients. Serum samples were frozen in small aliquots at $-60^{\circ} \mathrm{C}$ until the assay. Because of the rarity of Wegener's granulomatosis, the samples had been stored from one to five years before the study.

A group of 30 healthy children ( 18 boys and 12 girls; mean (SD) age, 7.4 (3.8) years) admitted for elective tonsillectomy and adenoidectomy served as normal controls. They had no fever or other symptoms at the time of sampling. In addition, sera from 17 consecutive patients with other autoimmune diseases (juvenile chronic arthritis, dermatomyositis, scleroderma) were tested for ANCA by ELISA using crude neutrophil extract and they served as disease controls.

Parental consent was obtained and the study was approved by the Great Ormond Street Hospital for Children/Institute of Child Health Ethics Committee.

Serum samples were studied using: indirect immunofluorescence; ELISA using a crude neutrophil extract for IgG and IgM (crude ANCA IgG and IgM, respectively); ELISA for IgG and IgM antibodies directed against 
myeloperoxidase, lactoferrin, cathepsin G, and elastase; and assay for proteinase 3 specific IgG was also attempted using a commercial kit (BioCarb Diagnostics Ltd, Worcestershire, UK), which unfortunately used an $\alpha$ granule extract of neutrophils as antigen. Although this assay measured principally antibody directed to proteinase 3 , there may have been some cross reactivity to myeloperoxidase and lactoferrin present.

INDIRECT IMMUNOFLUORESCENCE MICROSCOPY Patient sera were first screened for ANCA using standard indirect immunofluorescence microscopy. ${ }^{13}$ Neutrophils from healthy donors were separated by gravity sedimentation on methylcellulose/Hypaque. Slides prepared by cytocentrifugation were fixed in absolute ethanol at $0^{\circ} \mathrm{C}$. The neutrophil preparations were incubated with patient's serum (dilution, 1/16), washed, incubated with fluorescein isothiocyanate (FITC) conjugated rabbit antihuman immunoglobulin (antikappa and antilambda chains; Dako, High Wycombe, Bucks, UK), washed and mounted. Staining patterns by fluorescent microscopy were compared with known negative control sera. Positive controls included antiproteinase 3 and antimyeloperoxidase sera (Binding Site Ltd, Birmingham, UK). Cytoplasmic pattern (C-ANCA) was defined as granular staining of cytoplasm with accentuation between nuclear lobes. Perinuclear pattern (P-ANCA) was present when there was fluorescence around the nucleus.

ELISA PROCEDURE FOR CRUDE ANCA

Crude neutrophil extract was prepared from neutrophils of healthy donors by methylcellulose/Hypaque gradient separation, washing, and resuspension in sodium acetate (0.2 M, pH 4.2); cells were disrupted by sonication, and cell membranes and nuclear debris were removed from the supernatant antigen extract by centrifugation, as described previously. ${ }^{3}$ Microtitre plates (Nunc Life Technologies, Paisley, UK) were coated by incubation with this antigen preparation in carbonate/ bicarbonate buffer ( $\mathrm{pH} 9.6)$ at room temperature overnight. Plates were washed thoroughly, using phosphate buffered saline (PBS) containing $2 \%$ casein and $0.1 \%$ Tween 20 between all steps. Wells were incubated serially with $\mathrm{PBS} / 2 \%$ casein, patient's serum in $\mathrm{PBS} / 2 \%$ casein, then peroxidase conjugated rabbit antihuman IgG or IgM immunoglobulins (Sigma Chemicals Co, Poole, Dorset, UK), and finally $o$-phenylenediamine dihydrochloride (Sigma Chemicals Co). The enzyme reaction was stopped by the addition of $2 \mathrm{M}$ sulphuric acid after 20-30 minutes incubation and the absorbance was read at $492 \mathrm{~nm}$. All samples were processed in duplicate, and the absorbances were averaged. Each plate included wells with PBS alone, known positive and negative sera, and control wells (without antigens but incubated with patient serum) for each sample. Results were expressed as ELISA units by reading patients' absorbance against the dilution curve of a known positive standard on a semi-logarithmic scale, and subtracting from it similar readings of the corresponding control well. The positive standard and control sera were taken from known Wegener's granulomatosis patients and they have been confirmed to have strong positive ANCA in a leading laboratory undertaking regular ANCA assays (Hammersmith Hospital, London). The intra-assay coefficient of variation was $6.2 \%$ and the interassay coefficient of variation was $12 \%$.

ELISA PROCEDURES FOR ANTIBODIES AGAINST MYELOPEROXIDASE, LACTOFERRIN, CATHEPSIN G, AND ELASTASE

Similar procedures as above were used. The following antigen solutions were used to coat the wells at $4^{\circ} \mathrm{C}$ overnight: myeloperoxidase $(0.2 \mu \mathrm{g} / \mathrm{ml}$; Calbiochem, Nottingham, UK); lactoferrin $(25 \mu \mathrm{g} / \mathrm{ml}$; Calbiochem); cathepsin $\mathrm{G}(2 \mu \mathrm{g} / \mathrm{ml}$; Calbiochem); elastase $(10 \mathrm{ng} / \mathrm{ml}$; Sigma Chemicals Co). Bovine serum albumin $(1 \%)$ in PBS was used for blocking. Bound antibodies were detected with alkaline phosphatase conjugated goat antihuman IgG or

Table 1 Systemic manifestation of 12 patients with Wegener's granulomatosis

\begin{tabular}{|c|c|c|c|c|c|c|c|c|c|c|}
\hline Case & $\begin{array}{l}\text { Sex/age } \\
\text { (years) }\end{array}$ & Presenting symptoms & Skin & MS & $U R T$ & $L R T$ & Kidney & GI tract & CNS & Biopsy \\
\hline 1 & $\mathrm{~F} / 11.7$ & Acute renal failure & + & + & + & - & + & + & - & $\begin{array}{l}\text { Kidney, crescentic glomerulonephritis } \\
\text { Nose, granulomatous inflammation } \\
\text { Vasculitis }\end{array}$ \\
\hline 2 & $\mathrm{M} / 1.16$ & Stridor & + & - & + & + & - & - & - & Skin, granulomatous inflammation \\
\hline 3 & $\mathrm{~F} / 12.7$ & Haemoptysis & + & + & + & + & + & + & - & $\begin{array}{l}\text { Kidney, focal glomerulonephritis } \\
\text { Nose, granulomatous inflammation } \\
\text { Larynx, granulomatous inflammation }\end{array}$ \\
\hline 4 & $\mathrm{M} / 7.29$ & Polyarthritis & + & + & + & + & + & + & - & $\begin{array}{l}\text { Muscle, vasculitis } \\
\text { Colon, vasculitis }\end{array}$ \\
\hline 5 & $\mathrm{~F} / 13.94$ & Stridor & - & + & + & - & - & - & - & Larynx, vasculitis \\
\hline 6 & $\mathrm{~F} / 7.82$ & Fever, epistaxis & - & + & + & + & - & + & + & $\begin{array}{l}\text { Rectum, vasculitis } \\
\text { Nose, non-specific inflammation }\end{array}$ \\
\hline 7 & $\mathrm{M} / 14.2$ & Haemoptysis & + & + & + & + & - & - & - & Nose, non-specific inflammation \\
\hline 8 & $\mathrm{M} / 10.5$ & Polyarthritis & + & + & + & - & + & + & - & Not done \\
\hline 9 & $\mathrm{~F} / 9.83$ & Stridor & + & + & + & - & - & - & + & Larynx, non-specific inflammation \\
\hline 10 & $\mathrm{~F} / 2.1$ & Fever, skin nodules & + & + & - & + & - & - & - & $\begin{array}{l}\text { Skin, non-specific inflammation } \\
\text { Lung, non-specific inflammation }\end{array}$ \\
\hline 11 & $\mathrm{~F} / 0.31$ & Stridor & + & - & + & - & - & - & - & Larynx, non-specific inflammation \\
\hline 12 & $\mathrm{~F} / 0.16$ & Stridor, haemoptysis & + & - & + & + & - & + & - & $\begin{array}{l}\text { Trachea, granulomatous inflammation } \\
\text { Colon, vasculitis }\end{array}$ \\
\hline
\end{tabular}

Skin, vasculitic or purpuric rash; musculoskeletal (MS), muscle pain/tenderness, polyarthritis; upper respiratory tract (URT), granulomatous rhinitis and sinusitis, laryngeal stenosis; lower respiratory tract (LRT), haemoptysis or shadows on chest radiography; kidney, urine abnormalities, raised serum creatinine, glomerulonephritis; GI tract, abdominal pain, bloody diarrhoea; CNS, neurological deficits. 
Table 2 ANCA results in 12 patients with Wegener's granulomatosis

\begin{tabular}{|c|c|c|c|c|c|c|c|c|}
\hline \multirow[b]{2}{*}{ Case } & \multirow[b]{2}{*}{$\begin{array}{l}\text { ANCA IIF } \\
\text { pattern }\end{array}$} & \multicolumn{2}{|c|}{ Titre (in ELISA units) } & \multirow[b]{2}{*}{ Antigenic specificities } & \multicolumn{4}{|c|}{ Concomitant clinical parameters } \\
\hline & & $\begin{array}{l}\text { Crude ANCA IgG } \\
\text { (control < 4.1) }\end{array}$ & $\begin{array}{l}\text { Crude ANCA IgM } \\
\text { (control }<9.6 \text { ) }\end{array}$ & & $\begin{array}{l}E S R \\
(m m / h)\end{array}$ & $H b(g / l)$ & $\begin{array}{l}W B C \\
\left(\times 10^{9} / l\right)\end{array}$ & $\begin{array}{l}\text { Platelets } \\
\left(\times 10^{9} / l\right)\end{array}$ \\
\hline 1 & P-ANCA & 10.0 & 256.0 & MPO-IgG, MPO-IgM, Cath-IgG, Elas-IgG & 88 & 93 & 9.6 & 344 \\
\hline 2 & Negative & 1.8 & 13.8 & PR3-IgG, Lact-IgG, Cath-IgM & 48 & 98 & 19.7 & 1098 \\
\hline 3 & C-ANCA & 20.0 & 11.8 & PR3-IgG, MPO-IgM, Cath-IgM & 70 & 66 & 9.6 & 447 \\
\hline 4 & C-ANCA & 8.0 & 2.6 & MPO-IgG, Lact-IgG, Cath-IgG, Elas-IgG & 38 & 123 & 9.4 & 470 \\
\hline 5 & Negative & 5.5 & 5.2 & Titre within control range & 83 & 126 & 9.7 & 385 \\
\hline 6 & C-ANCA & 4.8 & 11.0 & MPO-IgM, Cath-IgM & 90 & 69 & 14.0 & 375 \\
\hline 7 & C-ANCA & 43.6 & 36.0 & PR3-IgG, MPO-IgM, Cath-IgM & 100 & 79 & 6.3 & 957 \\
\hline 8 & Negative & 1.9 & 0.5 & Titre within control range & 96 & 78 & 8.6 & 425 \\
\hline 9 & C-ANCA & 0.5 & 35.7 & Cath-IgG, Cath-IgM & 56 & 110 & 6.5 & 395 \\
\hline 10 & C-ANCA & 10.0 & 0.7 & PR3-IgG & 40 & 91 & 14.6 & 375 \\
\hline 11 & Negative & 4.2 & 13.6 & MPO-IgM, Lact-IgG, Cath-IgG, Cath-IgM & 50 & 121 & 23.6 & 607 \\
\hline 12 & Negative & 3.0 & 8.2 & Titre within control range & 40 & 120 & 24.3 & 1033 \\
\hline
\end{tabular}

P-ANCA, perinuclear pattern; C-ANCA, cytoplasmic pattern; MPO, antimyeloperoxidase titre; Cath, anticathepsin G titre; Lact, antilactoferrin titre; Elas; antielastase titre; PR3, antiproteinase 3 titre; ESR, erythrocyte sedimentation rate; Hb, haemoglobin; WBC total white blood cell count.

IgM immunoglobulins (Sigma Chemicals Co), with $p$-nitrophenyl phosphate (Sigma Chemicals Co) as substrate, and absorbance was read at $405 \mathrm{~nm}$. Results were expressed in ELISA units as above, but a different positive standard was needed for different antibodies.

\section{STATISTICAL METHODS}

Because the normal control group data did not have a Gaussian distribution, and could not be normalised by transformation, an arbitrary cut off to include $90 \%$ of these readings (more than 28 samples) was chosen as the observed normal range for each antibody subtype. Nonparametric Mann-Whitney test was used to compare the difference between any two groups.

\section{Results}

Table 2 shows the results of screening for ANCA and their antigen specificity in our 12 patients with Wegener's granulomatosis. Indirect immunofluorescence demonstrated the presence of ANCA in seven patients. Six patients showed a C-ANCA pattern and one patient showed a P-ANCA pattern. Using ELISA with the crude neutrophil extract, 10 patients were found to have high titres: crude
ANCA IgG was seen in eight patients and crude ANCA IgM was seen in seven patients (five of whom were positive for both). Three of these patients showed negative indirect immunofluorescence results but low positive titres by ELISA. Figure 1 shows the crude ANCA IgG and IgM titres of Wegener's granulomatosis patients, the disease control group, and the normal control group. The titres were significantly higher in Wegener's granulomatosis patients compared with normal controls by Mann-Whitney test, while there were no significant differences between disease control and normal control groups.

Using specific antigens in the ELISA assay, we demonstrated positive titres of antibodies directed to cathepsin $\mathrm{G}$ in seven patients (IgG in three, $\operatorname{Ig} M$ in six), to myeloperoxidase in six patients (IgG in two, IgM in five), to lactoferrin in three patients (IgG in all), and to elastase in two patients (IgG in all). ANCA screening using the BioCarb kit was positive in four patients. This probably indicated the presence of IgG antibodies to proteinase 3. However some cross reactivity to other impurities such as myeloperoxidase or lactoferrin might have been present, although this was unlikely
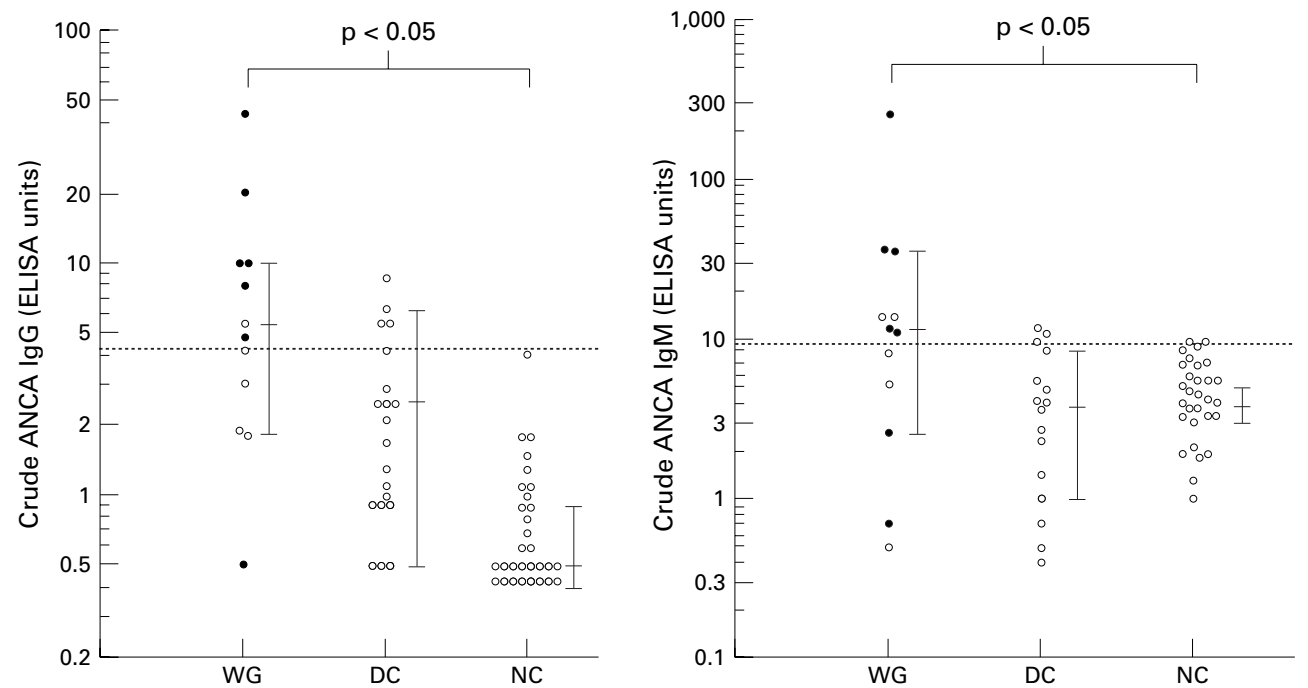

Figure 1 ANCA detected by ELISA using crude acid neutrophil extract as substrate (crude ANCA IgG and crude ANCA IgM) in patients with Wegener's granulomatosis (WG), patients with other autoimmune diseases as disease control (DC), and normal children (NC). ELISA units are on a logarithmic scale. Values are medians and 95\% confidence limits. Solid circles, patients with positive IIF results; open circles, patients with negative IIF results; dotted lines indicate arbitrary upper limit of normal children. 
because these four patients showed negative or low titres of IgG against other antigens.

\section{Discussion}

Wegener's granulomatosis is a rare disorder in childhood but an important differential diagnosis in ill children with non-specific multisystem symptoms. By definition, Wegener's granulomatosis is characterised by the presence of granulomatous inflammation of the respiratory tract and necrotising vasculitis affecting small to medium sized vessels. ${ }^{14}$ The diagnosis in paediatric cases is particularly difficult because it might not be possible to obtain adequate tissue from multiple sites or multiple organs to demonstrate the characteristic histological features. A negative biopsy does not exclude the diagnosis. ${ }^{15}$

In 1985, the presence ANCA with a characteristic cytoplasmic staining pattern (CANCA) was demonstrated in patients with Wegener's granulomatosis, ${ }^{2}$ and this has provided a convenient non-invasive means of establishing the diagnosis. In adults, the demonstration of ANCA has a high sensitivity of $91 \%$ and specificity of $98 \%$ during the active phase but the sensitivity is lower $(63 \%)$ during the inactive phase. ${ }^{16}$ In a meta-analysis by Bajema et al, ${ }^{15}$ on 349 Wegener's granulomatosis patients reported from 1979 to 1995 , ANCA analysis was positive in 46 patients and negative in 11 of the 228 patients with histologically proven Wegener's granulomatosis (in the remaining 171 patients ANCA analysis was not performed). Among the 121 patients without histological proof but with typical clinical course of Wegener's granulomatosis, ANCA analysis was positive and helped in the diagnosis in 45 patients. It was not performed in 75 patients and was negative in one patient.

However, the role of ANCA in paediatric patients has not been fully established. Ellis et al reported five children and reviewed six previously reported children with systemic vasculitis and the presence of ANCA..$^{10}$ Only three had histological proof of Wegener's granulomatosis and in two of them a C-ANCA staining pattern was seen and in one a P-ANCA staining pattern was seen. The other patients had microscopic polyangiitis or idiopathic crescentic glomerulonephritis.

All our patients satisfied two or more of the clinical criteria proposed by the American College of Rheumatology for the diagnosis of Wegener's granulomatosis. ${ }^{12}$ Most had histological evidence of granulomas or necrotising vasculitis. Our study supported the usefulness of ANCA screening in the diagnosis of Wegener's granulomatosis. We demonstrated the presence of ANCA in 10 of the 12 patients. This was shown by means of indirect immunofluorescence in seven patients, with a C-ANCA staining pattern in six and a P-ANCA staining pattern in one. The ELISA assay using crude neutrophil extract demonstrated the presence of ANCA in all patients with positive indirect immunofluorescence results and in three patients with negative indirect immunofluorescence results. It is necessary to detect both IgG and $\operatorname{IgM}$ in the ELISA assay because either might be positive, as shown in our patients. In adult patients, the combined use of indirect immunofluorescence and ELISA also leads to a diagnostic specificity of $99 \% .{ }^{17}$

On the other hand, in a small minority of Wegener's granulomatosis patients, ANCA screening might be negative - two of our patients had a negative ANCA screen by indirect immunofluorescence and ELISA, one of whom had histological proof of granulomatous inflammation in the trachea. This is also supported by Bajema et al's report of 11 patients with negative ANCA yet histological proof of granulomatous inflammation. ${ }^{15}$ Overall, the current diagnosis of Wegener's granulomatosis depends on one or more of the following criteria: a positive C-ANCA test, the presence of granulomas, and a clinical course typical of the disease.

In one study of adult patients, increases in serum ANCA concentrations demonstrated by indirect immunofluorescence were shown to precede clinical exacerbation by a few months or weeks, ${ }^{18}$ although this was not confirmed by a later study. ${ }^{19}$ ANCA concentrations decreased significantly or disappeared when patients were treated successfully with steroid and cyclophosphamide. ${ }^{20}$ IgM ANCA have been seen in relation to haemorrhagic capillaritis in the lungs. ${ }^{21} 22$ In our study, we have not attempted to study ANCA concentrations serially in our patients. In fact, all our patients were in the active phase of their disease, as shown by a raised erythrocyte sedimentation rate, and most had anaemia, leucocytosis, and thrombocytosis. In addition, because of the small number of patients, we could not demonstrate any statistical association of ANCA isotypes or ANCA titres with organ system involvement or clinical parameters.

Our studies on antigen specificities revealed interesting findings. First, anticathepsin $\mathrm{G}$ and antimyeloperoxidase (both IgG and IgM) occurred commonly in our patients. Antiproteinase $3 \mathrm{IgG}$ was present in only four patients. Antilactoferrin and antielastase antibodies were unusual. Second, seven patients had antibodies with multiple specificity, most to myeloperoxidase and cathepsin G. In his 1996 review, ${ }^{4}$ Wiik summarised the antigen specificity of ANCA in adult patients. Most Wegener's granulomatosis patients have antibodies directed to proteinase 3 , giving a C-ANCA pattern on indirect immunofluorescence, although a few Wegener's granulomatosis patients and about half the patients with microscopic polyangiitis, Churg-Straus syndrome, and focal necrotising glomerulonephritis have antibodies directed against myeloperoxidase, giving a P-ANCA pattern on indirect immunofluorescence. Antibodies to elastase occurred in patients with propylthiouracil induced vasculitis, and lactoferrin is recognised as an autoantigen in a few patients with rheumatoid arthritis complicated by vasculitis, in systemic lupus erythematosus, and in ulcerative colitis. Our finding of multiple antigen specificities might be the result of non-specific binding of antibody secondary to generalised immune 
activation. Its significance in the pathogenesis of paediatric Wegener's granulomatosis needs further study.

In conclusion, we found a high prevalence of ANCA in paediatric patients with Wegener's granulomatosis. These autoantibodies have variable specificities including proteinase 3, myeloperoxidase, cathepsin G, and rarely lactoferrin and elastase. The occurrence of antibodies with multiple antigenic specificities and the frequency of $\operatorname{IgM}$ isotypes in our patients was also noteworthy. The significance and clinical usefulness of these findings require further study.

S N Wong was supported by the Commonweath Scholarship Commission. V Shah was supported by the Kidney Research Herring and Friends Fund (Child Health Research Appeal Trust).

1 Rottem M, Fauci AS, Hallahan CW, et al. Wegener granuloRottem M, Fauci AS, Hallahan CW, et al. Wegener granulomatosis in children and adolescents: clinic

2 Van Der Woude FJ, Rasmussen N, Lobatto S, et al. Autoantibodies against neutrophils and monocytes: tool for diagnosis and marker of disease activity in Wegener's granulomatosis. Lancet 1985;i:425-9.

3 Savage CO, Winearls, Jones S, Marshall BD, Lockwood CM. Prospective study of radioimmunoassay for antibodies against neutrophil cytoplasm in diagnosis of systemic vasculitis. Lancet 1987;i:1389-93.

4 Wiik AS. Anti-neutrophil cytoplasmic antibodies in primary small vessel vasculitides. Scand f Rheumatol 1996;25:65-9.

5 Venning MC, Quinn A, Broomhead V, Bird AG. Antibodies directed against neutrophils (C-ANCA and P-ANCA) are of distinct diagnostic value in systemic vasculitis. $Q f M$ 1990;77:1287-96.

6 Egner W, Chapel HM. Titration of antibodies against neutrophil cytoplasmic antigens is useful in monitoring 1990;82:244-9.

7 Pall AA, Savage CO. Mechanisms of endothelial cell injury in vasculitis. Springer Semin Immunopathol 1994;16:23-37.
8 Gross WL, Csernok E, Helmchen U. Antineutrophil cytoplasmic autoantibodies, autoantigens, and systemic vasculitis. APMIS 1995;103:81-97.

9 Lesavre P. Antineutrophil cytoplasmic autoantibodies antigen specificity. Am F Kidney Dis 1991;18:159-63.

10 Ellis EN, Wood EG, Berry P. Spectrum of disease associated with anti-neutrophil cytoplasmic autoantibodies in paediatric patients. F Pediatr 1995;126:40-3.

11 Nash MC, Dillon MJ. Antineutrophil cytoplasm antibodies and vasculitis. Arch Dis Child 1997;77:261-4.

12 Leavitt RY, Fauci AS, Bloch DA, Michel BA. The American College of Rheumatology 1990 criteria for the classification of Wegener's granulomatosis. Arthritis Rheum 1990;33: 1101-7.

13 Wiik A. Delineation of a standard procedure for indirect immunofluorescence detection of ANCA. APMIS 1989; 97(suppl): 12-13.

14 Jennette JC, Falk RJ, Andrassy K, et al. Nomenclature of systemic vasculitides. Proposal of an international consensus conference. Arthritis Rheum 1994;37:187-92.

15 Bajema IM, Hagen EC, Van der Woude FJ, Bruijn JA. Wegener's granulomatosis: a meta-analysis of 349 literary case reports. f Lab Clin Med 1997;129:17-22.

16 Rao JK, Weinberger M, Oddone EC, et al. The role of antineutrophil cytoplasmic (c-ANCA) testing in the diagnosis of Wegener granulomatosis: a literature review and meta-analysis. Ann Intern Med 1995;123:925-32.

17 Savage COS, Harper L, Adu D. Primary systemic vasculitis. Lancet 1997;349:553-8.

18 Cohen Tervaert JW, Huitema MG, Hene RJ, et al. Prevention of relapses in Wegener's granulomatosis by treatment based on antineutrophil cytoplasm antibody titre. Lancet 1990;336:709-11.

19 Kerr GS, Fleisher TA, Hallahan CW, Leavitt RY, Fauci AS, Hoffman GS. Limited prognostic value of changes in antineutrophil cytoplasmic antibody titer in patients with Wegener's granulomatosis. Arthritis Rheum 1993;36:36571.

20 Nash MC, Jones CL, Walker RG, Powell HR. Antineutrophil cytoplasmic antibody-associated glomerulonephritis in children. Pediatr Nephrol 1993;7:11-14.

21 Esnault VLM, Soleimani B, Keoogan MT, Brownlee AA, Jayne DRW, Lockwood CM. Association of IgM with IgG ANCA in patients presenting with pulmonary hemorrhage. Kidney Int 1992;41:1304-10.

22 Thomas DM, Moore R, Donovan K, Wheeler DC, Esnault VLM, Lockwood CM. Pulmonary-renal syndrome in association with anti-GBM and IgM ANCA. Lancet 1992; 339:1304. 